\title{
DEMOGRAPHIC AND CLINICAL CHARACTERISTICS OF PATIENTES WITH SYSTEMIC AUTOIMMUNE MYOPATHIES IN AN OUTPATIENT RHEUMATOLOGY CLINIC AT A TERTIARY REFERRAL HOSPITAL
}

Amália Maria Fernandes de Sá Duarte Filha ${ }^{1}$, Clarice Alves Esmeraldo ${ }^{1}$, Carolina Dias da Silva Amorim ${ }^{1}$ Andrea Tavares Dantas ${ }^{1}$, Angela Luzia Branco Pinto Duarte ${ }^{1}$, Laurindo Ferreira da Rocha Junior ${ }^{1, *}$

1.Universidade Federal de Pernambuco, Recife (PE), Brazil.

*Corresponding author: laurindorochajr@hotmail.com

\section{BACKGROUND}

Systemic autoimmune myopathies (SAM) are a group of rare diseases characterized by muscle inflammation. Several types of SAMs are defined with a wide range of different manifestations. This study aimed to describe demographic and clinical characteristics of patients with SAM assisted at a tertiary hospital in the state of Pernambuco.

\section{METHODS}

Descriptive, cross-sectional study was performed in Rheumatology Outpatient Clinic at Hospital das Clínicas da Universidade Federal de Pernambuco. We included patients that fulfilled classification criteria for SAM followed during the period between May 2020 and June 2021. Demographic and clinical characteristics were collected during visit consultations and by medical record reviews (Table 1). GraphPad Prism V 6.01 was used to perform statistical analysis. A p $<0.05$ was considered statistically significant.

Table 1. Demographic and clinical characteristics patients with systemic autoimmune myopathies.

\begin{tabular}{|c|c|}
\hline CHARACTERISTIC & \\
\hline No. patients & 54 \\
\hline Age, years, mean (range) & $51.27(19-78)$ \\
\hline Disease duration, years, median (range) & $7.68(0.4-29)$ \\
\hline Female/Male & $43 / 11$ \\
\hline \multicolumn{2}{|l|}{ Myopathy phenotype, N (\%) } \\
\hline Dermatomyositis & $29(53.7)$ \\
\hline Polymyositis & $14(25.9)$ \\
\hline Antisynthetase syndrome & $6(11.1)$ \\
\hline Amyopathic dermatomyositis & $4(7.4)$ \\
\hline Immune mediated necrotizing myopathy & $1(1.8)$ \\
\hline \multicolumn{2}{|l|}{ Associated connective tissue disease, $\mathbf{N}(\%)$} \\
\hline Systemic sclerosis & $5(9.2)$ \\
\hline Rheumatoid arthritis & $4(7.4)$ \\
\hline Systemic lupus erythematosus & $3(5.5)$ \\
\hline Sjögren's syndrome & $2(3.7)$ \\
\hline \multicolumn{2}{|l|}{ Most common associated comorbidities, $\mathbf{N}(\%)$} \\
\hline Hypertension & $22(40.7)$ \\
\hline Pneumopathy & $15(27.7)$ \\
\hline Osteoporosis & $13(24.0)$ \\
\hline Dyslipidemia & $12(22.2)$ \\
\hline \multicolumn{2}{|l|}{ Treatment (\%) } \\
\hline Antimalarials & $12(22.2$ \\
\hline Azathioprine & $16(29.6)$ \\
\hline Methotrexate & $12(22.2)$ \\
\hline Mycophenolate mofetil & $10(18.5)$ \\
\hline Cyclosporine & $6(11.1)$ \\
\hline Glucocorticoids & $33(61.1)$ \\
\hline Rituximab & $5(9.2)$ \\
\hline Intravenous gamma globulin & $1(1.8)$ \\
\hline
\end{tabular}

Realização: 


\section{RESULTS}

A total of 54 patients were included. Most of the patients were female ( $n=43,79.6 \%)$. The mean age of the patients was 51.3 ( \pm 13.9 ) years. Dermatomyositis (DM) was the most frequent myopathy (53.7\%), followed by polymyositis ( $25.9 \%$ ) and antisynthetase syndrome (11.1\%). Ten (18.5\%) patients had overlap with other systemic autoimmune diseases being systemic sclerosis the most frequent one (5 patients). Pulmonary disease was a clinical feature in $15(27.7 \%)$ patients. Hypertension was the most common comorbidity $(n=22,40.7 \%)$. Most of the patients were under azathioprine $(29.6 \%)$ and methotrexate (22.2\%). Thirty-three (61.1\%) patients were using corticosteroids. The median time of diagnosis was 8 (IQR 4.0-11.5) years in patients with DM compared to the other myopathies 4 (IQR 2.0-6.0) years, $p=0.0278$. Amyopathic dermatomyositis patients $(n=4)$ had minor median time of diagnosis of 3.5 (IQR 1.05-4.0) years, compared to other myopathies, 6 (IQR 4.0-10.25) years $(p=0.0330)$. Disease duration was higher in patients not using corticosteroids, 8 (IQR 4.5-12.0) years compared to patients under this therapy 4 (IQR 3.0-8.5) years, $p=0.0163$. There was a trend for a higher proportion of men with pulmonary disease (54.5\%) compared to female patients (26.5\%), $p=0.0538$. Patients with hypertension were older ( $59.0 \pm 9.6$ years) compared to patients without hypertension ( $43 \pm 14$ years), $p=0.0004$. Disease duration correlated negatively with corticosteroid dose $(r=-0.3894, p=0.0036)$. A significant proportion of patients with diabetes (50\%) were under statin use compared to patients without diabetes (13\%), $p=0.0308$.

\section{CONCLUSION}

In our sample we could identify clinical and demographic characteristics of patients with systemic autoimmune myopathies. Patients under corticosteroids had shorter disease duration and pulmonary disease had a frequency of $27.7 \%$. Physicians who manage myositis may identify and deal with patients' comorbidities, such hypertension and diabetes.

\section{KEYWORDS}

Systemic autoimmune myopathies, Dermatomyositis, Polymyositis, Inflammatory myopathies. 